\title{
The effects of high intensity exercise during pulmonary rehabilitation on ventilatory parameters in people with moderate to severe stable COPD: a systematic review
}

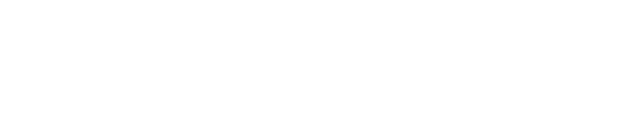

\section{Kristin Osterling' \\ Kimbly MacFadyen' \\ Robert Gilbert ${ }^{2}$ \\ Gail Dechman'}

'School of Physiotherapy, ${ }^{2}$ School of Health Sciences, Dalhousie University, Halifax, NS, Canada
Correspondence: Kristin Osterling 4th Floor, Forrest Building, 5869 University Avenue, Halifax, NS, B3H 4R2, Canada

Tel +I 9024942524

Fax + I 902494 |94|

Email kristin.osterling@dal.ca
Objective: The objective of this systematic review was to determine whether people with moderate to severe COPD who are participating in pulmonary rehabilitation and exercising at high intensity demonstrate the changes in ventilatory parameters that are associated with decreased dyspnea.

Data sources: The authors searched EMBASE, The Cochrane Library, and CINAHL databases up to December 2013 for relevant randomized control trials, systematic reviews, and observational studies. References of identified studies were also screened.

Study selection: Studies conducted in a pulmonary rehabilitation setting that included education and exercise were included. Symptom-limited, graded exercise testing that measured tidal volume, respiratory rate, minute ventilation, and inspiratory capacity was required. The studies that contained these keywords in the title or the abstract were selected for further evaluation of the text. Disagreements between reviewers were resolved by consensus. Four studies met these inclusion criteria.

Data extraction: Quality assessment and data extraction were performed independently by two reviewers. Risk of bias and quality was assessed according to the Cochrane Handbook for Systematic Reviews of Interventions.

Data synthesis: Participants in three studies trained at high intensity $(70 \%-80 \%$ maximum workload), demonstrating statistically significant changes in tidal volume and respiratory rate. One study did not demonstrate positive ventilatory benefits; however, participants may not have met the desired training intensity. Two studies reported improvement in dyspnea at submaximal exercise intensities. One study noted an increased maximum workload with no significant change in dyspnea at peak exercise.

Conclusion: People with moderate to severe, stable COPD were able to perform high intensity exercise, which was associated with positive changes in ventilatory parameters and dyspnea. A number of factors limit the generalizability of these results to people participating in pulmonary rehabilitation.

Keywords: chronic obstructive pulmonary disease, chronic obstructive lung disease, exercise, tidal volume, respiratory rate

\section{Introduction}

COPD is an umbrella term used to describe lung diseases such as emphysema and chronic bronchitis that cause expiratory airflow limitation. ${ }^{1}$ Currently, COPD affects at least 700,000 adults in Canada, and despite being largely underdiagnosed and undertreated, it has become one of the leading causes of mortality worldwide. ${ }^{1,2}$ The etiology of COPD 
is multifaceted. Research demonstrates that chronic exposure to toxic particles or gases and resultant airway inflammation lead to airflow limitation, hyperinflation, and ventilation and gas exchange disruption, which are typical symptoms of COPD. ${ }^{3}$ The Canadian Thoracic Society states that COPD is a common respiratory disorder, characterized by progressive, partially reversible airflow limitation and lung hyperinflation. ${ }^{1}$ A decrease in maximal expiratory flow rate is the hallmark physiological abnormality associated with COPD.,

One of the most disabling symptoms of COPD is dyspnea during activity. ${ }^{6}$ With the increase in ventilatory demand and respiratory frequency during exercise, there is insufficient time for the end-expiratory lung volume to decline to its equilibrium value. ${ }^{7}$ Inspiration is initiated before expiration is complete, and progressive air trapping occurs, inevitably leading to dynamic hyperinflation of the lungs. ${ }^{8}$ To determine the rate and the magnitude of the dynamic hyperinflation during exercise, clinicians evaluate the inspiratory capacity (IC), the volume of gas that can be taken into the lungs during full inhalation from functional residual capacity. ${ }^{8}$ The IC determines the operating limits for tidal volume expansion during exercise. As dynamic hyperinflation becomes worse, the IC decreases, further expansion of the lungs becomes nearly impossible, and respiratory effort is not rewarded appropriately for the amount of effort that is required to breathe..$^{9,10}$ The mismatch between the "need" to increase tidal volume and the inability to do so is thought to be a key contributor to breathing discomfort, also known as dyspnea.

An early manifestation of COPD is exercise intolerance resulting from abnormal pulmonary function, breathing discomfort, and muscle fatigue. ${ }^{10,11}$ In a clinical trial conducted by O'Donnell and Laveneziana, ${ }^{11} 61 \%$ of participants terminated exercise because of breathing discomfort, 19\% stopped due to a combination of breathing and leg discomfort, and 18\% were limited due to leg discomfort alone. Ironically, exercise is one of the most effective methods of reducing dyspnea in people with COPD. In a research setting, aerobic training at an appropriate intensity decreases lactic acid production and consequently the ventilatory demand. As a result, respiratory rate is less and hyperinflation decreases. ${ }^{6}$ Overall, this will help the individual to sustain normal tasks of daily living, and contribute to dyspnea desensitization. ${ }^{12}$

There has been considerable debate about the appropriate exercise intensity for people with COPD. A study by Casaburi et $\mathrm{al}^{13}$ in the early 1990 s revolutionized thoughts about exercise prescription on this issue. Participants in that study underwent an 8-week training program, exercising at $80 \%$ of their peak work rate determined during a pre-training incremental exercise test. ${ }^{13}$ Overall, the participants experienced significant reductions in both blood lactate and minute ventilation that were associated with a decrease in respiratory rate and an increase in tidal volume. ${ }^{13}$ These results were very exciting and had important implications for exercise in people with COPD; however, this study was criticized because the participants had mild disease and were not considered representative of people who would attend pulmonary rehabilitation. Consequently, Maltais et al ${ }^{14}$ attempted to replicate these results in patients with moderate to severe disease. Participants in that study were unable to achieve $80 \%$ of their work rate maximum. This paper presents a systematic review of studies that examined changes in ventilatory parameters in pulmonary rehabilitation participants achieving high intensity exercise.

\section{Methods}

\section{Protocol and registration}

The inclusion criteria and analysis methods for the systematic review were specified in advance and documented in the following protocol. This systematic review was registered during the preliminary search stage with PROSPERO (CRD42014007117) on January 14, 2014 at http://www.crd. york.ac.uk/prospero.

\section{Criteria for studies considered in this review \\ Types of studies}

Only randomized controlled trials, systematic reviews, and observational studies were included.

\section{Participants}

Males and females with moderate to severe, stable COPD were included in this study. For the purpose of this systematic review, stable COPD is defined as the absence of an exacerbation in the 4 weeks preceding pulmonary rehabilitation. ${ }^{15}$ Disease severity in the papers was defined according to the GOLD (Global Initiative for Chronic Obstructive Lung Disease) guidelines. ${ }^{2}$ Studies that included individuals with additional comorbidities that would contribute to dyspnea, such as other lung diseases or heart dysfunction, and individuals using assisted ventilation were excluded from this review.

\section{Intervention}

Pulmonary rehabilitation is an evidence-based, multidisciplinary, and comprehensive intervention for individuals 
living with chronic lung disease. ${ }^{15}$ Typically, it is delivered as a 6-12-week exercise and education program designed to reduce symptoms including dyspnea, increase function, and reduce hospital admissions. ${ }^{15}$ Only studies that met this definition of pulmonary rehabilitation were considered for this review. Included studies had to provide detailed descriptions of both the educational (eg, breathing techniques, nutrition, and energy conservation) and exercise (including the frequency, intensity, type, and time) program components. Studies including pulmonary rehabilitation programs less than 4 weeks long were excluded, as it has been suggested that these are considered too short to achieve training benefits. ${ }^{16,17}$

\section{Outcome measures}

Studies included in this review needed to include outcome measures for each of the three parameters the authors considered important: minute ventilation measured in liters per minute, respiratory rate measured in breaths per minute, and tidal volume measured in liters. A secondary outcome, IC was considered if included in the study. All outcomes measures had to be assessed during a symptom-limited graded exercise test.

\section{Search strategy for identification of studies}

A systematic literature search was conducted using the Medical Subject Headings (MeSH) term "chronic obstructive pulmonary disease (COPD)" and the term "pulmonary rehabilitation" to extract studies and editorials from the following databases: EMBASE (1974-2013), CINAHL (1982-2013), and The Cochrane Library (1993-2013). The Cochrane Register provides systematic reviews and meta-analyses. EMBASE indexes Medline, PubMed, and European Health associations. CINHAL indexes studies associated with allied health professions. A general search of Google in the past month (December 2013) and Google Scholar in the past year (2013) was also conducted. A hand search of the references in all initial articles identified during the screening process was conducted. Clinical Trials Registry (https://clinicaltrials.gov) was accessed to search for any abstracts of newly completed or upcoming research studies. Conference proceedings from The Canadian Respiratory Conference, The European Respiratory Conference, and The American Thoracic Society were also checked from 2008 to 2013. Gray literature, including brochures and guidelines, from The Lung Association and the local Health Sciences Center were also searched for information. The search was updated on January 20, 2014.
All authors collaborated in developing the search strategy. The following keywords were used alone or in various combinations: chronic obstructive pulmonary disease (COPD), chronic obstructive lung disease (COLD), rehabilitation, pulmonary rehabilitation, exercise, physiological response, cardiopulmonary, minute ventilation, respiratory rate, tidal volume, and hyperinflation. "Chronic obstructive pulmonary disease" and "chronic obstructive lung disease" are defined terms that describe the particular disease; the associated abbreviations were also used in the search. A search breaking down the disease into its two primary components, emphysema and chronic bronchitis, was also conducted, but no additional studies were found. Searching for associated terms or MeSH terms for pulmonary rehabilitation, did not reveal any new terms; therefore, the search was refined to "rehabilitation AND exercise AND education." All additional terms used were the outcome measures being examined in this review. Not all the outcomes could be placed in the same search at once because the search became too limited. Filters including peer-reviewed articles, English language papers, and human subjects were applied to the advanced search. No restrictions were placed on the years investigated.

The following search strategy was used for EMBASE:

1. "Chronic obstructive pulmonary disease" OR "COPD" OR "chronic obstructive lung disease" OR "COLD"

2. "Pulmonary rehabilitation" OR "rehabilitation"

3. "Exercise"

4. "Respiratory rate" OR "minute ventilation" OR "tidal volume"

5. \#1 AND \#2 AND \#3

6. \#1 AND \#2 AND \#3 AND "benefits"

7. \#1 AND \#2 AND \#3 AND \#4

8. \#1 AND \#2 AND \#3 AND "physiological response"

9. \#1 AND \#2 AND \#3 AND "cardiopulmonary response"

10. \#1 AND \#2 AND \#3 AND "cardiovascular response"

11. \#8 AND \#4

12. \#9 AND \#4

13. \#10 AND \#4.

\section{Study selection}

Based on the eligibility criteria, the document title and abstract were initially screened to determine which studies were eligible for further evaluation. The studies were screened for the key terms "chronic obstructive pulmonary disease" and "pulmonary rehabilitation" in the title. Abstracts were reviewed for all studies with titles containing the terms or a variation of them. The studies that contained the keywords in the title or the abstract were selected for further evaluation 
of the text. To ascertain the validity of eligible studies, three reviewers independently appraised the studies in a standardized manner using the CONSORT nonpharmacological treatment intervention extension guidelines. ${ }^{18}$ Disagreements between reviewers were resolved by consensus.

\section{Data collection}

A data extraction table was developed based on the Cochrane Consumers and Communications Review Group's template. The extraction table was refined as studies were appraised. The primary author (KO) extracted the data, while the second author (KM) checked the accuracy of the extraction. Any disagreements regarding the data tables were discussed between the two authors. If no agreement could be reached, a consensus decision was achieved by discussion among all study authors. The information in the extraction table included 1) study design and length of study, 2) characteristics of trial participants, 3) inclusion and exclusion criteria, 4) intervention type and duration, 5) primary and secondary findings, and 6) funding sources. In all cases where any data were missing, the author (KO) attempted to contact the study authors and requested further information.

\section{Assessment of the methodological quality}

The methodological quality of the studies was independently assessed by two reviewers $\mathrm{KO}$ and GD. The quality of each study was assessed using the Cochrane Handbook for Systematic Reviews of Interventions ${ }^{19}$ as a guide. Study design, allocation concealment, randomization, blinding, withdrawals/ dropouts, intention-to-treat analyses, selective reporting, and any additional biases were taken into consideration and evaluated.

\section{Results}

\section{Studies retrieved}

Figure 1 is a detailed flow diagram with results from the systematic literature search conducted by the primary researcher $(\mathrm{KO})$. The search identified 3,131 articles after duplicates were removed. Of these, 3,121 were subsequently excluded after the titles and abstracts were screened according to the eligibility criteria. The predominant reasons for exclusion of the 3,121 articles included 1) studies did not measure respiratory rate and tidal volume, 2) studies used home-based pulmonary rehabilitation, and 3) studies did not have similar groups (mild COPD versus moderate-severe COPD). Full-text screening and assessment of the risk of bias

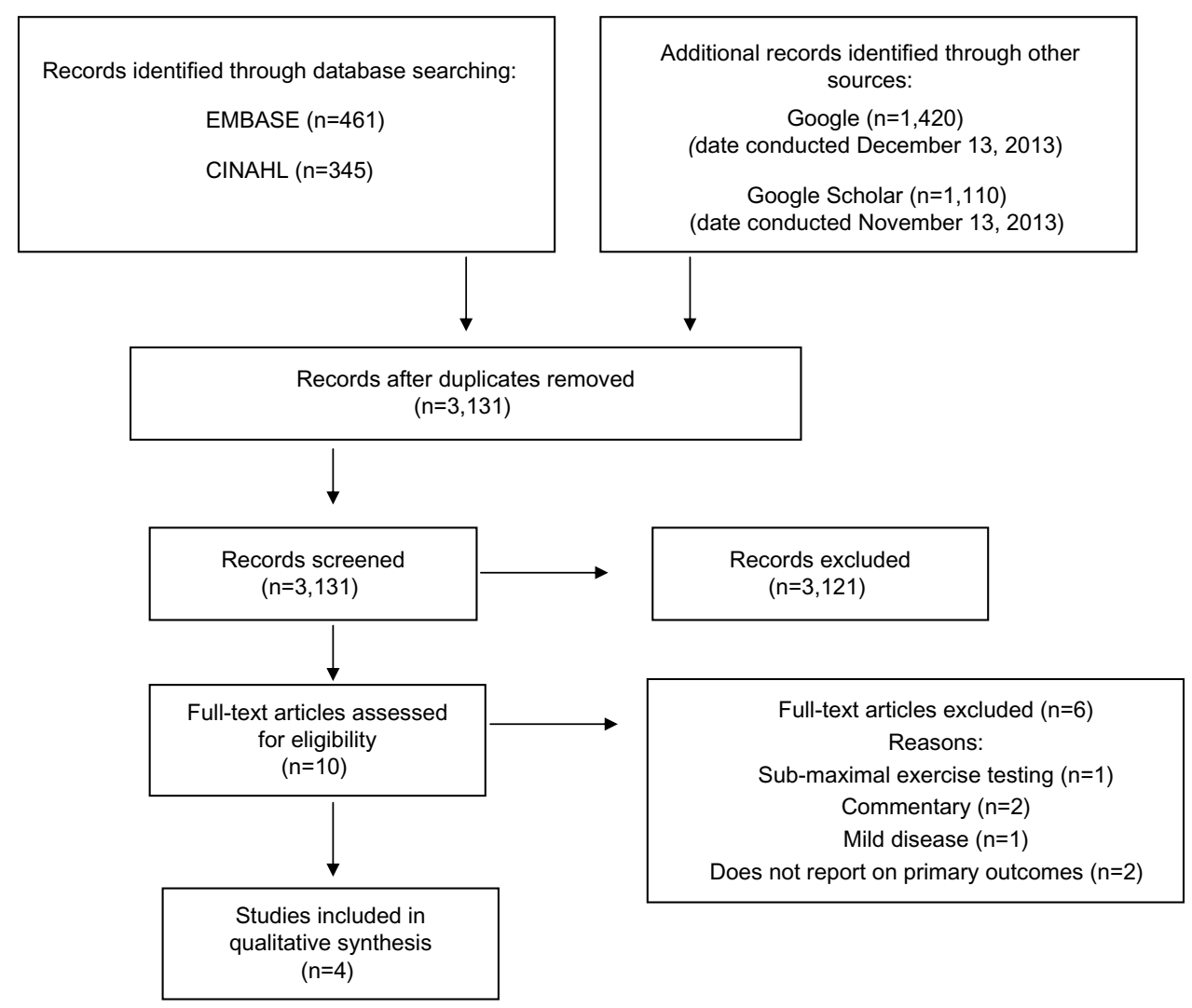

Figure I Systematic search flowchart. 
of the remaining ten articles was reviewed, and four articles were kept for inclusion in this review. The characteristics of those four studies are presented in Table 1.

\section{Quality assessment and risk of bias summary: according to the Cochrane Handbook for Systematic Reviews of Interventions}

Table 2 presents a summary of the risk of bias for the studies in this review. The majority of the papers were methodologically weak, as they failed to report blinding or methods of randomization. None of the studies described how the participants were recruited; however, Gigliotti et $\mathrm{al}^{20}$ stated that participant recruitment was consecutive in nature. Allocation concealment was only applicable in one of the studies, ${ }^{21}$ as the observational studies did not have groups that would require allocation. Blinding did not occur in any of the studies, which created a high risk for both performance and detection bias. Therefore, the quality of the overall body of evidence was found to be low, and future research is likely to have an impact on the confidence of the results presented in the studies.

\section{Program description}

The four studies included in the systematic review were published between 2003 and 2013. There were three observational studies ${ }^{20,22,23}$ and one randomized controlled study. ${ }^{21}$ The studies were conducted in three countries: Canada, ${ }^{21}$ Italy, ${ }^{20,23}$ and Norway. ${ }^{22}$ Participant numbers ranged from 18 to 48 people per study, and a pooled total of 125 participants. The age range of the participants was from 40 to 80 years, and males represented $63 \%$ of the total review population. The severity of COPD was reported in all the studies and was based on pulmonary function testing. Disease severity ranged from moderate to severe across the studies; however, none of the studies specified the number of participants in each severity category.

\section{Intervention: pulmonary rehabilitation}

The intervention was examined for the following: mode of exercise, frequency, duration and intensity of exercise, and the total length of the intervention (Table 1). All programs delivered pulmonary rehabilitation on an outpatient basis. Studies reported high compliance, but only two studies ${ }^{21,22}$ provided data to substantiate this. All programs included aerobic training on treadmills or cycle ergometers. Two of the programs also included resistance training. The duration of the pulmonary rehabilitation interventions ranged from 4 to 12 weeks. Participants attended pulmonary rehabilitation
3-5 times each week, with sessions lasting 90-180 minutes. The participants attended a maximum of 12-27 sessions, accumulating between 240 and 900 minutes of exercise. The intensity of the sessions in all but one study was based on the participant's peak workload, aiming to achieve between $70 \%$ and $80 \%$ of their maximal workload. Wadell et $\mathrm{al}^{21}$ asked their participants to attain their highest possible work rate, targeting at least a "moderate" intensity breathing discomfort on the modified 10-point Borg scale. Programs progressed the exercise using a combination of intensity and duration. The participants in the study by Wadell et $\mathrm{al}^{21}$ aimed to complete 4-10 minutes of exercise, and this amount did not change throughout the 8-week program.

\section{Outcomes}

Tables 1 and 3 summarize the changes in the primary and secondary outcome measures in this review. Table 3 presents the data at iso-levels (the identical time or work rate in both exercise tests) to facilitate understanding the changes within a particular study. Data presented in the publications did not allow us to calculate the percent change in tidal volume and respiratory rate.

All studies reported changes in minute ventilation pre- to post-pulmonary rehabilitation. Three of these studies $^{20,22,23}$ demonstrated a statistically significant increase in minute ventilation at peak exercise, while the fourth did not report data with respect to peak exercise. Gigliotti et $\mathrm{al}^{20}$ and Skumlien et $\mathrm{al}^{22}$ also reported decreases in minute ventilation at submaximal workloads (Table 3). The study by Wadell et a ${ }^{21}$ reported a non-significant decrease in this parameter. The two studies that reported a significant decrease in submaximal minute ventilation also reported a significant decrease in respiratory rate and an increase in tidal volume. ${ }^{20,22}$ In the study by Skumlien et al, ${ }^{22}$ respiratory rate decreased but the change in tidal volume was not significant. ${ }^{22}$ Wadell et $\mathrm{al}^{21}$ only presented changes in tidal volume and respiratory rate graphically, but it appears that neither parameter changed significantly following pulmonary rehabilitation. All four studies reported changes in IC; however, only one of these studies noted a significant increase in this parameter. ${ }^{20}$ The studies quantified the changes in ventilatory parameters differently, making direct comparisons between studies impossible For instance, Gigliotti et $\mathrm{al}^{20}$ and Skumlien et $\mathrm{al}^{22}$ reported changes in respiratory rate and tidal volume with respect to the work rate maximum achieved during the initial exercise test. On the other hand, Ramponi et $\mathrm{al}^{23}$ reported changes in ventilatory parameters with respect to the maximum 


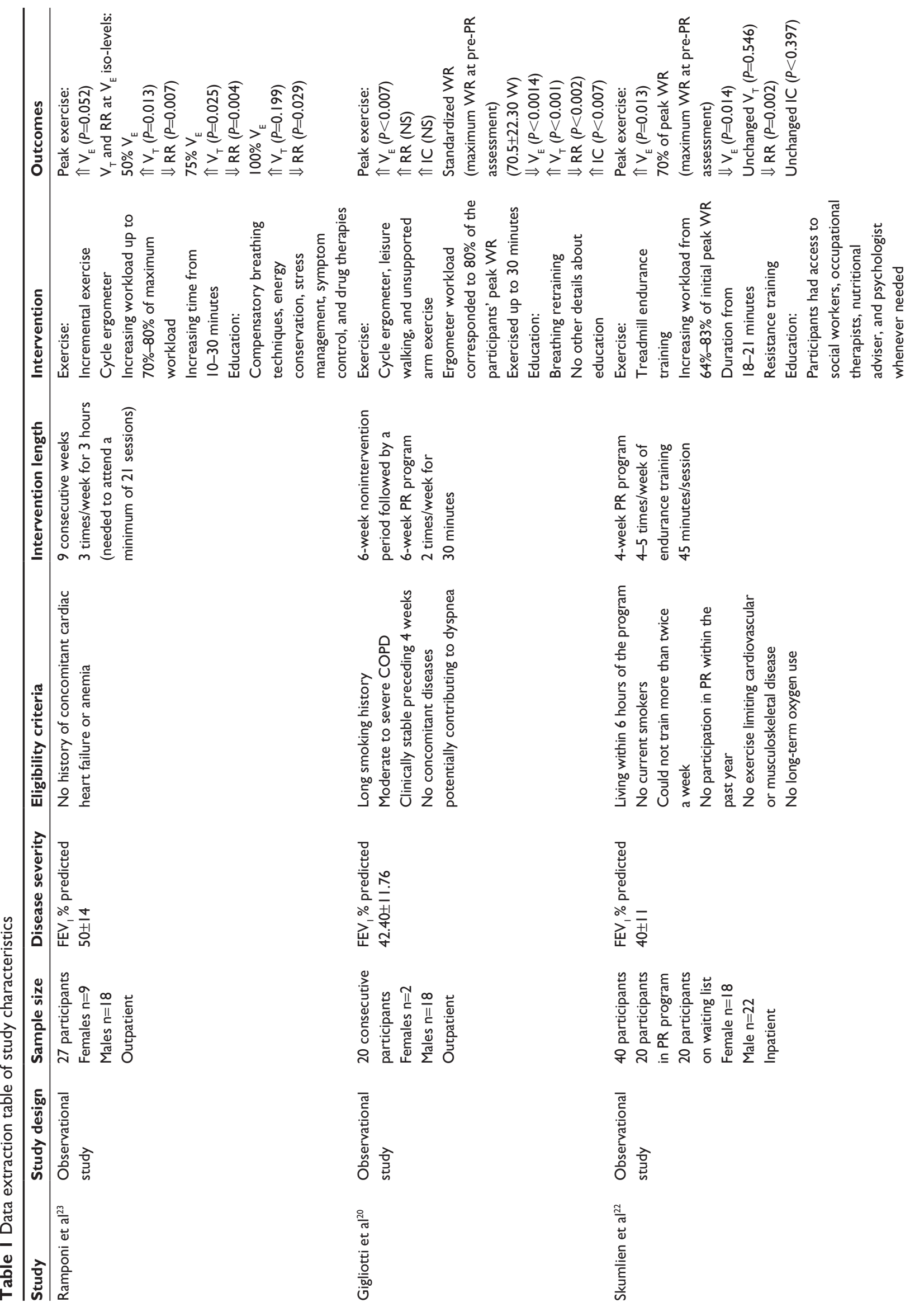



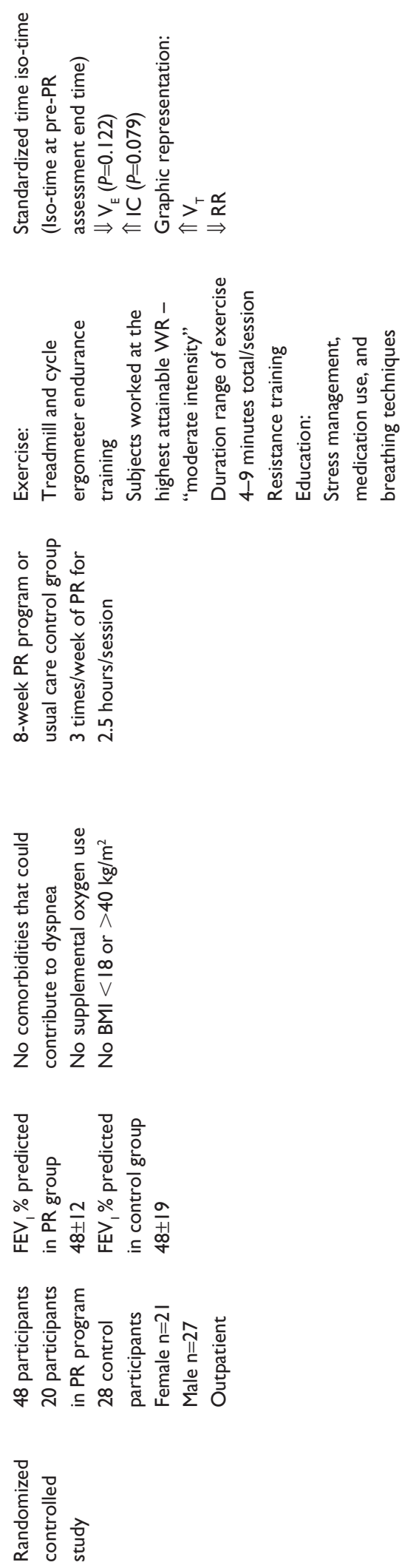

$\frac{\pi}{\pi}$
$\frac{\pi}{0}$
$\overline{\frac{\pi}{0}}$ minute ventilation achieved in the initial exercise test (see Table 3 for details).

Investigating changes in dyspnea was not the intent of this systematic review; however, all four studies reported information on this variable. Two of the studies ${ }^{20,22}$ reported improved dyspnea following pulmonary rehabilitation. Gigliotti et $\mathrm{al}^{20}$ reported a decrease in dyspnea with respect to the peak minute ventilation on the pre-intervention exercise test. They noted a decrease from $6.6( \pm 2.56)$ to $3.3( \pm 1.73)$ on the Borg scale, with a $P$-value of $<0.0001$. Skumlien et al ${ }^{22}$ also reported a decrease in dyspnea $(-1.7$ Borg scale units, $95 \%$ confidence interval -2.2 to $-1.1 ; P<0.0005)$ at $70 \%$ of the participants' peak work rate. On the other hand, Ramponi et $\mathrm{al}^{23}$ assessed dyspnea using a $0-100$ visual analogue scale. They found that the median dyspnea score at peak exercise was unchanged pre- to post-intervention $(P<0.208) .{ }^{23}$ Wadell et $\mathrm{al}^{21}$ reported their dyspnea scores during a constant workload test that was performed pre- and post-pulmonary rehabilitation. There was a non-significant decrease in the Borg score from $6.1( \pm 2.4)$ to $6.2( \pm 2.9), P>0.05 .{ }^{21}$

\section{Discussion}

The purpose of this systematic review was to determine whether participants in pulmonary rehabilitation programs could achieve the high exercise intensities recommended by research-based studies. The literature search identified only four studies that met our inclusion criteria, which included individuals with moderate to severe, stable COPD who were participating in pulmonary rehabilitation. Also, pre- and post-intervention symptom-limited graded exercise testing had to assess minute ventilation, respiratory rate, and tidal volume. These variables as well as IC, if it was reported, were chosen because they are closely related to dynamic hyperinflation, which is felt to be a key contributor to dyspnea and exercise limitation in people with COPD. All studies aimed to have participants exercise at a moderate to high exercise intensity, with three studies basing exercise intensity on the maximum work rate achieved in a pre-intervention graded exercise test. The fourth study advised participants to use the Borg dyspnea scale to grade their exercise intensity. ${ }^{21}$ Three of the four studies reported significant decreases in respiratory rate and increases in tidal volume with respect to a comparable point (iso-level) in the pre-intervention exercise test. ${ }^{20,21,23}$ Two of those studies assessed IC, ${ }^{20,21}$ and only Gigliotti et al ${ }^{20}$ reported that it decreased significantly.

Groundbreaking work by Casaburi et al ${ }^{13}$ in 1991 demonstrated that in people with COPD, exercise at or above the lactate threshold could stimulate physiologic 
Table 2 Risk of bias and quality assessment

\begin{tabular}{|c|c|c|c|c|c|c|c|}
\hline & Study design & $\begin{array}{l}\text { Random } \\
\text { sequence } \\
\text { generation } \\
\text { (selection bias) }\end{array}$ & $\begin{array}{l}\text { Allocation } \\
\text { concealment } \\
\text { (selection } \\
\text { bias) }\end{array}$ & $\begin{array}{l}\text { Blinding of } \\
\text { participants } \\
\text { and personnel } \\
\text { (performance } \\
\text { bias) }\end{array}$ & $\begin{array}{l}\text { Blinding of } \\
\text { outcome } \\
\text { assessment } \\
\text { (detection } \\
\text { bias) }\end{array}$ & $\begin{array}{l}\text { Incomplete } \\
\text { outcome data } \\
\text { (attrition } \\
\text { bias) }\end{array}$ & $\begin{array}{l}\text { Selective } \\
\text { reporting } \\
\text { (reporting } \\
\text { bias) }\end{array}$ \\
\hline Ramponi et $\mathrm{al}^{23}$ & Observational study & $?$ & N/A & - & - & + & + \\
\hline Gigliotti et $\mathrm{al}^{20}$ & Observational study & + & N/A & - & - & + & + \\
\hline Skumlien et $\mathrm{al}^{22}$ & Observational study & $?$ & N/A & - & - & + & + \\
\hline Wadell et $\mathrm{al}^{21}$ & $\begin{array}{l}\text { Randomized } \\
\text { controlled trial }\end{array}$ & $?$ & - & - & - & + & + \\
\hline
\end{tabular}

Notes: ?, unclear risk of bias; +, low risk of bias; -, high risk of bias; N/A, not applicable based on study design.

training effects when compared with those individuals who did not exercise at this high intensity. The lactate threshold, which occurs at $60 \%-80 \%$ of the maximum work rate, ${ }^{24}$ is often used to identify the threshold for high intensity exercise. Three of the studies in this systematic review had participants aim to exercise at intensities that should have been at or above the lactate threshold. ${ }^{20,22,23}$ Participants in each of these studies demonstrated either a decrease in respiratory rate and an increase in tidal volume referenced to pre-intervention workloads or an increase in minute ventilation at the post-intervention peak workload. Wadell et $\mathrm{al}^{21}$ expressed concern that participants in their study did not reach a high exercise intensity, which may explain why they did not demonstrate positive changes in ventilatory parameters. Furthermore, participants in that study were asked to complete only 4-9 minutes of exercise per session, which would have made it difficult to stimulate physiologic changes associated with increasing the lactate threshold. These results suggest that it is possible for people in pulmonary rehabilitation to work at high intensity and that this intensity is required to achieve significant improvements in ventilatory parameters during exercise.
Casaburi et $\mathrm{al}^{13}$ reported superior functional improvement in the high intensity compared with the low intensity exercise group in their study. Both exercise capacity and endurance during a high intensity constant workload test were significantly better in the high intensity training group. The investigators attributed the differences to a greater decrease in blood lactate in the high intensity training group, which could be associated with improved muscle function. ${ }^{25}$ In addition, the reduction in lactic acidosis decreases ventilatory demand and consequently minute ventilation, and this too could contribute to improved exercise performance. The increase in minute ventilation needed to meet the elevated metabolic demands associated with activity in people with COPD is achieved mainly through an increase in respiratory rate. ${ }^{26}$ However, the reduction in expiratory time promotes dynamic hyperinflation, causing the lung to become less compliant, thereby limiting increases in tidal volume. The lack of change in tidal volume despite increased respiratory muscle effort is felt to contribute significantly to the sensation of dyspnea. ${ }^{6}$ It follows that any intervention that reduces dynamic hyperinflation could lessen breathing discomfort. Dyspnea is the most commonly cited reason people

Table 3 Changes in ventilatory parameters measured at iso-levels before and after PR

\begin{tabular}{|c|c|c|c|c|c|}
\hline & $\begin{array}{l}\text { Accumulated } \\
\text { exercise time }\end{array}$ & $\Delta \mathbf{V}_{\mathrm{E}}(\mathrm{L} / \mathrm{min})$ & $\Delta R R$ (breaths/min) & $\Delta T V(L)$ & $\Delta \mathrm{IC}(\mathrm{L})$ \\
\hline $\begin{array}{l}\text { Ramponi et al }{ }^{23} \\
\text { at } 75 \% \mathrm{~V}_{\mathrm{E}}\end{array}$ & $\begin{array}{l}810 \text { minutes at } \\
\text { maximum duration }\end{array}$ & $\begin{array}{l}\text { Only reported at } \\
\text { peak end-exercise }\end{array}$ & $-2.0 \pm 4.0 * *$ & $+0.08 \pm 0.44 *$ & - \\
\hline $\begin{array}{l}\text { Gigliotti et } \mathrm{al}^{20} \\
\text { at WR maximum pre-PR } \\
\text { assessment }\end{array}$ & 360 minutes & $-3.2 \pm 7.39 * *$ & $-4.5 \pm 6.59 * *$ & $+0.1 \pm 0.36 * *$ & $+0.2 \pm 0.49 * *$ \\
\hline $\begin{array}{l}\text { Skumlien et a }{ }^{22} \\
\text { at } 70 \% \text { of maximum WR }\end{array}$ & 900 minutes & $-2.6 \pm 2.1 *$ & $-3.1 \pm 1.8^{* * *}$ & $+0.02 \pm 0.09$ & $+0.06 \pm 0.15$ \\
\hline $\begin{array}{l}\text { Wadell et } \mathrm{al}^{21} \\
\text { Iso-time at pre-PR } \\
\text { assessment end time }\end{array}$ & $\begin{array}{l}240 \text { minutes at } \\
\text { maximum duration }\end{array}$ & $-1.8 \pm 4.5$ & Only graphed results & Only graphed results & $+0.06 \pm 0.14$ \\
\hline
\end{tabular}

Notes: $\Delta$, change in; +, increase; -, decrease; $* P<0.01 ; * * P<0.05$.

Abbreviations: IC, inspiratory capacity; PR, pulmonary rehabilitation; RR, respiratory rate; $T V$, tidal volume; $V_{E}$, minute ventilation; WR, work rate. 
with COPD stop aerobic activity, and alleviating the symptom can improve function in this patient population. ${ }^{1,6,11}$

Three of the four studies in this review assessed changes in IC, ${ }^{20-22}$ but only Gigliotti et $\mathrm{al}^{20}$ noted a significant increase in this parameter, indicating that exercise training reduced dynamic hyperinflation. Participants in that study exercised at intensities associated with the lactate threshold and reported decreased dyspnea compared to the same, pre-training exercise intensity. Interestingly, it is unlikely that participants in the study by Wadell et $\mathrm{al}^{21}$ exercised at a high-enough intensity or time to promote physiological changes in exercise capacity. Accordingly, they failed to demonstrate a positive change in IC or dyspnea. Participants in the study by Skumlien et $\mathrm{al}^{22}$ exercised at high intensity and demonstrated a decrease in respiratory rate but failed to demonstrate significant changes in tidal volume or IC. These participants noted reductions in dyspnea, suggesting that improving tidal volume alone may be sufficient to alleviate breathing discomfort during exercise. It is also possible that high intensity training caused these participants to experience a degree of psychological desensitization to their dyspnea. Ramponi et $\mathrm{al}^{23}$ did not measure IC but reported significant positive changes in respiratory rate and tidal volume without associated improvements in dyspnea. In contrast to other studies that measured the change in dyspnea at iso-level, these investigators assessed dyspnea only at peak exercise. It is not surprising that dyspnea at peak exercise intensity, regardless of the absolute work, did not change. Taken together, the results from the studies in this review support the use of high intensity exercise, at or above the lactate threshold, to decrease activity-associated dyspnea.

We specified that studies in this review include participants in pulmonary rehabilitation programs, as we wanted the results to be relevant to the standard of care in this patient population. Subjects in the studies are representative of participants in pulmonary rehabilitation programs in terms of their age, sex, and disease severity, and our inclusion criteria specified programs that delivered pulmonary rehabilitation in a clinically relevant way as recommended by major professional associations. ${ }^{27,28}$ However, several factors limit the generalizability of our findings. First, programs varied greatly in terms of the duration of individual exercise sessions, the number sessions per week, and total program duration. Each of these factors interacts with intensity to affect the training response, so we are unable to give specific guidance about these aspects of exercise prescription. Several of the studies excluded participants with comorbidities. While this is understandable from a research perspective, it does not reflect the challenges of exercise prescription in pulmonary rehabilitation. Finally, the effect of selection bias cannot be discounted. Participants in these studies agreed to exercise at high intensity, and their motivation to do so distinguishes them from many people in pulmonary rehabilitation. The robustness of the conclusions are further limited by the methodology of included trials and the low numbers of subjects included in all the studies. Despite these limitations, the findings of this review support those of Casburi et $\mathrm{al}^{13}$ regarding value of high intensity training in people with COPD.

\section{Conclusion}

This systematic review demonstrates that people with moderate to severe COPD who are participating in pulmonary rehabilitation can achieve high exercise intensities that result in changes in ventilatory parameters and are associated with decreased activity-associated dyspnea. The generalizability of these findings is limited by low study quality and the heterogeneity of the exercise programs included in the review. However, the findings were consistently positive and should encourage clinicians to prescribe high intensity exercise for people in pulmonary rehabilitation, as the changes reported may improve quality of life.

\section{Future direction}

Work by Maltais et $\mathrm{al}^{14}$ has shown that not all individuals with COPD who participant in pulmonary rehabilitation can train at high exercise intensities. However, participants in that study demonstrated improvements in exercise capacity that were accompanied by decreases in minute ventilation and blood lactate. It appears there is a continuum of exercise intensities associated with training responses in people with COPD. Identifying the boundaries of this continuum is important, as exercising at intensities that are too low are ineffective, and high exercise intensities are uncomfortable and may discourage participation in pulmonary rehabilitation. Future research should attempt to describe the boundaries of effective training intensities in a systematic way in order to optimize the pulmonary rehabilitation process and better support clinicians' exercise prescription choices. Methodological weaknesses identified in this systematic review should be considered when designing protocols to examine the boundaries of effective training intensities. Strategies to eliminate or diminish recruitment bias are critically important, and undoubtedly, multicenter studies to recruit adequate numbers and facilitate blinding of staff 
and participants will be necessary. Furthermore, careful documentation of participants' abilities to achieve prescribed exercise intensities will be needed. While these requirements may seem daunting, they are worth the effort given the important role of exercise in decreasing mortality and morbidity and improving quality of life in people with COPD.

\section{Acknowledgments}

The authors would like to thank Peter Stilwell, DC, BSc (Canadian Memorial Chiropractic College, Toronto, ON, Canada) for his assistance with risk of bias and quality assessment of the studies.

\section{Disclosure}

There are no personal or financial contributions that would influence the authors work in this systematic review. No funding or support from scientific writing assistance agencies was used to conduct the research. There are no conflicts of interest to report.

\section{References}

1. O'Donnell DE, Hernandez P, Kaplan A, et al. Canadian thoracic society recommendations for management of chronic obstructive pulmonary disease - 2008 update - highlights for primary care. Can Respir J. 2008;15 (Suppl A):1A-8A.

2. Global Initiative for Chronic Obstructive Lung Disease, Inc. Global Strategy for the Diagnosis, Management, and Prevention of Chronic Obstructive Pulmonary Disease: updated 2013. Available from: http:// www.goldcopd.org/uploads/users/files/GOLD_Report_2013_Feb20. pdf. Accessed May 21, 2013.

3. Rodríguez-Roisin R. The airway pathophysiology of COPD: implications for treatment. COPD. 2005;2(2):253-262.

4. Stockley RA, Rennard SI, Rabe K, Celli B, editors. Chronic obstructive pulmonary disease: a practical guide to management. Hoboken, $\mathrm{NJ}$ : Wiley-Blackwell; 2008.

5. O'Donnell DE, Laveneziana P. Physiology and consequences of lung hyperinflation in COPD. Eur Respir Rev. 2006;15(100):61-67.

6. O'Donnell DE. Hyperinflation, dyspnea, and exercise intolerance in chronic obstructive pulmonary disease. Proc Am Thorac Soc. 2006;3(2): 180-184.

7. O'Donnell DE, Laveneziana P. The clinical importance of dynamic lung hyperinflation in COPD. COPD. 2006;3(4):219-232.

8. Leff AR, Schumacker PT. Respiratory Physiology: Basics and Applications. Philadelphia: WB Saunders Co; 1993.

9. O’Donnell DE, Revill SM, Webb KA. Dynamic hyperinflation and exercise intolerance in chronic obstructive pulmonary disease. Am J Respir Crit Care Med. 2001;164(5):770-777.

10. Pepin V, Saey D, Laviolette L, Maltais F. Exercise capacity in chronic obstructive pulmonary disease: mechanisms of limitation. COPD. 2007;4(3):195-204.
11. O'Donnell DE, Laveneziana P. Dyspnea and activity limitation in COPD: mechanical factors. COPD. 2007;4(3):225-236.

12. Cooper CB. Determining the role of exercise in patients with chronic pulmonary disease. Med Sci Sports Exerc. 1995;27(2): $147-157$.

13. Casaburi R, Patessio A, Ioli F, Zanaboni S, Donner CF, Wasserman K. Reductions in exercise lactic acidosis and ventilation as a result of exercise training in patients with obstructive lung disease. Am Rev Respir Dis. 1991;143(1):9-18.

14. Maltais F, LeBlanc P, Jobin J, et al. Intensity of training and physiologic adaptation in patients with chronic obstructive pulmonary disease. Am J Respir Crit Care Med. 1997;155(2):555-561.

15. Spruit MA, Singh SJ, Garvey C, et al. An official American Thoracic Society/European Respiratory Society statement: key concepts and advances in pulmonary rehabilitation. Am J Respir Crit Care Med. 2013;188(8):e13-e64.

16. Powers S, Howley E. Exercise Physiology: Theory and Application to Fitness and Performance. New York: McGraw-Hill; 2008.

17. Strasser B, Siebert U, Schobersberger W. Effects of resistance training on respiratory function in patients with chronic obstructive pulmonary disease: a systematic review and meta-analysis. Sleep Breath. 2013;17(1):217-226.

18. Boutron I, Moher D, Altman DG, Schulz KF, Ravaud P; CONSORT Group. Methods and processes of the CONSORT group: example of an extension for trials assessing nonpharmacologic treatments. Ann Intern Med. 2008;148(4):W60-W66.

19. Higgins J, Green S, editors. Cochrane Handbook for Systematic Reviews of Interventions. Version 5.1.0. [Updated Mar 2011]. Available from: http://www.cochrane-handbook.org. Accessed January 1, 2014.

20. Gigliotti F, Coli C, Bianchi R, et al. Exercise training improves exertional dyspnea in patients with COPD: evidence of the role of mechanical factors. Chest. 2003;123(6):1794-1802.

21. Wadell K, Webb KA, Preston ME, et al. Impact of pulmonary rehabilitation on the major dimensions of dyspnea in COPD. COPD. 2013;10(4):425-435.

22. Skumlien S, Skogedal EA, Bjortuft O, Ryg MS. Four weeks' intensive rehabilitation generates significant health effects in COPD patients. Chron Respir Dis. 2007;4(1):5-13.

23. Ramponi S, Tzani P, Aiello M, Marangio E, Clini E, Chetta A. Pulmonary rehabilitation improves cardiovascular response to exercise in COPD. Respiration. 2013;86(1):17-24.

24. Waschki B, Kirsten A, Holz O, et al. Physical activity is the strongest predictor of all-cause mortality in patients with COPD: a prospective cohort study. Chest. 2011;140(2):331-342.

25. Ament W, Verkerke GJ. Exercise and fatigue. Sports Med. 2009;39(5): 389-422.

26. O’Donnell DE, McGuire M, Samis L, Webb KA. General exercise training improves ventilatory and peripheral muscle strength and endurance in chronic airflow limitation. Am J Respir Crit Care Med. 1998; 157(5 Pt 1):1489-1497.

27. Ries AL, Bauldoff GS, Carlin BW, et al. Pulmonary rehabilitation: Joint ACCP/AACVPR Evidence-Based Clinical Practice Guidelines. Chest. 2007;131(Suppl 5):4S-42S.

28. Nici L, Donner C, Wouters E, et al. American Thoracic Society/European Respiratory Society statement on pulmonary rehabilitation. Am J Respir Crit Care Med. 2006;173(12):1390-1413. 
International Journal of COPD

\section{Publish your work in this journal}

The International Journal of COPD is an international, peer-reviewed journal of therapeutics and pharmacology focusing on concise rapid reporting of clinical studies and reviews in COPD. Special focus is given to the pathophysiological processes underlying the disease, intervention programs, patient focused education, and self management protocols.

\section{Dovepress}

This journal is indexed on PubMed Central, MedLine and CAS. The manuscript management system is completely online and includes a very quick and fair peer-review system, which is all easy to use. Visit $\mathrm{http}: / /$ www.dovepress.com/testimonials.php to read real quotes from published authors.

Submit your manuscript here: http://www.dovepress.com/international-journal-of-copd-journal 